\title{
Commentary: Amhr2-Cre-Mediated Global Tspo Knockout
}

\author{
Vimal Selvaraj ${ }^{1 *}$, Kanako Morohaku ${ }^{2}$, Prasanthi P. Koganti ${ }^{1}$, Jianmin Zhang ${ }^{3}$, Wei He ${ }^{3}$, \\ Susan M. Quirk ${ }^{1}$ and Douglas M. Stocco ${ }^{4}$ \\ ${ }^{1}$ Department of Animal Science, College of Agriculture and Life Sciences, Cornell University, Ithaca, NY, United States, \\ ${ }^{2}$ Division of Animal Science, School of Science and Technology, Institute of Agriculture, Shinshu University, Nagano, Japan, \\ ${ }^{3}$ State Key Laboratory of Medical Molecular Biology, Department of Immunology, Research Center on Pediatric Development \\ Diseases, Institute of Basic Medical Sciences, Chinese Academy of Medical Sciences and School of Basic Medicine, Peking \\ Union Medical College, Beijing, China, ${ }^{4}$ Department of Cell Biology and Biochemistry, Texas Tech University Health Sciences \\ Center, Lubbock, TX, United States
}

Keywords: ovary, testis, theca cells, granulosa cells, Sertoli cells, Leydig cells, steroidogenesis, mitochondria

\section{A Commentary on}

Amhr2-Cre-Mediated Global Tspo Knockout

by Fan, J., Campioli, E., Sottas, C., Zirkin, B., and Papadopoulos, V. (2020). J. Endocr. Soc. 4:bvaa001. doi: 10.1210/jendso/bvaa001

OPEN ACCESS

Edited by:

Pieter de Lange,

University of Campania Luigi

Vanvitelli, Italy

Reviewed by:

John S. Davis,

University of Nebraska Medical

Center, United States

*Correspondence:

Vimal Selvaraj

vs88@cornell.edu

Specialty section:

This article was submitted to

Cellular Endocrinology,

a section of the journal

Frontiers in Endocrinology

Received: 01 May 2020

Accepted: 16 June 2020

Published: 24 July 2020

Citation:

Selvaraj V, Morohaku K, Koganti PP,

Zhang J, He W, Quirk SM and Stocco DM (2020) Commentary:

Amhr2-Cre-Mediated Global Tspo Knockout. Front. Endocrinol. 11:472.

doi: 10.3389/fendo.2020.00472
We have carefully read the recent article by Fan et al. that $A m h r 2^{\text {cre } /+}$-mediated deletion produces "global" knockouts rather than tissue specific conditional knockouts (1). Such a major observation has not been explicitly recorded in the $>100$ publications that demonstrate tissue-specific conditional deletions using this $A m h r 2^{t m 3(c r e) B h r}$ mouse [MGI ID: 3042214; noted previously in (2)]. Furthermore, the authors directed their findings toward questioning published reports which disprove a role for the mitochondrial translocator protein (TSPO) in cholesterol transport and steroidogenesis, one of which was based on $A m h r 2^{\text {cre } /+}$-mediated conditional Tspo knockout mice (3).

\section{TRANSMISSION FROM THE MALE OR FEMALE PARENT MATTERS IN AMHR2-CRE ACTIVITY}

For cell type specific deletions using $A m h r 2^{\text {cre } /+}$ expressing mice (4), it is important to use male $A m h r 2^{\text {cre } /+}$ mice in the breeding scheme. This is information that has been shared among colleagues who have previously used $A m h r 2^{\text {cre } /+}$ mice in their studies. Accordingly, we have used males to transmit $A m h r 2^{\text {cre } /+}$ with confirmed conditional recombination for floxed targets (3, 5-9). Separate from our TSPO studies, there have indeed been incidents with breeding of female $A m h r 2^{\text {cre } /+}$ mice that resulted in global deletions. For example: when both male and female $A m h r 2^{\text {cre } /+}$ mice were used to delete Smo, global knockouts of which are embryonic lethal (10), $A m h r 2^{\text {cre } /+}$ conditional knockouts were obtained only when the sire harbored cre (unpublished). The breeding scheme was subsequently restricted to using male $A m h r 2^{\text {cre }} /+$ mice (8). This is consistent with male-restricted breeding schemes indicated by many different groups (11-21). So, we agree with findings reported by Fan et al. regarding global deletions (1), but caution that this is the case only when female $A m h r 2^{c r e /+}$ mice are used [gender of $A m h r 2^{\text {cre } /+}$ mice used in his publication was not indicated (1)]. This report therefore does not necessitate reinterpretation of any previous data on $A m h r 2^{\text {cre } /+}$ conditional knockouts unless female $A m h r 2^{c r e} /+$ mice were inadvertently used. 
For some transgenic lines, it is known that cre activity can vary based on whether the transgene is inherited from the male or female parent. As a knock-in $A m h r 2^{\text {cre/t+}}$ allele, expression is anticipated to reflect endogenous Amhr2 expression; therefore, this aberration is indeed unexpected. As Amhr2 knockout mice are viable (22), there appears to be little impact if there is indeed endogenous Amhr2 expression in the inner cell mass and trophoblast layer. It would also be valuable to test if this phenotype can be reproduced with the newly available

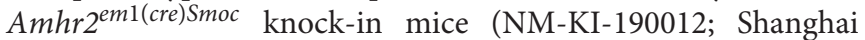
Model Organisms).

\section{TSPO IS NOT INVOLVED IN DE NOVO STEROIDOGENESIS}

Irrespective of method used or the timing of recombination, the conclusion for TSPO-loss of function with regard to de novo steroidogenesis is quite consistent [reviewed in (23)]. It does not affect viability (whole animal) nor does it affect mitochondrial cholesterol import in phenotypes reported by several independent laboratories (including ours) that have generated global Tspo knockouts using Ddx4-cre (24), Pgk1cre (25), Prm-cre (26), Camk2a-cre (27), and Best1-cre (28). The important points are: (a) Four of the above global knockouts generated were using independently produced Tspo floxed mice (24-27). (b) One of the global knockouts (28), was generated using the same Tspo floxed mouse used by the Papadopoulos group that includes this study by Fan et al. (1). (c) All the global knockouts were derived by recombination of Tspo-floxed alleles in the germline [expected $(24,26)$ or aberrant $(27,28)]$ or in early diploid cells (25). Therefore, these studies do describe Tspo knockouts that lack expression in the inner cell mass, as described for the Amhr2 $2^{\text {cre }}+$-mediated Tspo deletion by Fan et al. (1), and reveal no effects on embryonic development. (d) The proposed mechanism of TSPO function in steroidogenesis is by mediating mitochondrial cholesterol import, without which de novo steroidogenesis cannot occur [reviewed in (29)]. However, "subtle steroidogenic abnormalities" indicated in postpregnenolone intermediates observed with TSPO loss in one study (27), is not associated with mitochondrial cholesterol import, but indicative of systemic perturbations across all TSPO expressing tissues involved in energy metabolism (30), and could certainly include effects mediated by the pituitary (31). It must be noted that high TSPO expression is not restricted to steroidogenic cells (32), and the question has always been whether it impacts de novo steroidogenesis supporting its conjectural function first proposed in the late 1980s [reviewed in (33)].

Compared to TSPO studies that refute a role in de novo steroidogenesis $(3,24-26,32,34,35)$, there is no straightforward path to explaining the recent contradictory reports made by the Papadopoulos group using mice $(1,36)$, rats $(37)$, and cells $(38)$ that support their long-promulgated view of TSPO function in mitochondrial cholesterol import. We have previously pointed out these concerns $(2,39)$, and new evidence from independent groups continue to disassociate anticipated TSPO effects in astrocytes (40), microglia (35), and retinal pigment epithelial cells (41). In reference to this recent manuscript by Fan et al. (1), they report a $\sim 50 \%$ decrease in circulating testosterone while in their previous study using mice from the same background and with confirmed Leydig cell Tspo deletions, they reported no effect on circulating testosterone levels (36). Despite lower testosterone, there was no evidence of hypogonadism; in fact, testis size significantly increased in their Amhr2 $2^{\text {cre } /+}$ Tspo knockout mice (1). Furthermore, this study by Fan et al. used RNA-seq datasets that we generated for the $D d x 4$-cre Tspo-knockout adrenal (24) and Prm-cre Tspo-knockout lung (26), to suggest that there is some sort of steroidogenic compensation to Tspo deletion, when we found no such links in our respective original studies. These RNA-seq datasets show that a compensation to mitochondrial cholesterol import does not exist as the major players implicated in this process were unchanged. Nonetheless, Fan et al. seem to shift context toward explaining TSPO-associated effects on mitochondrial membrane potential and metabolism (1), distinct from the asserted cholesterol binding-transport function (33). Although logical, these elucidations are unrelated and do not justify that TSPO loss-of-function is linked to the first step in steroid biosynthesis as opined throughout the text. There is no loss to mitochondrial membrane potential in hepatocytes (42), or Leydig cells (32), associated with TSPO deletion as suggested (1). Regardless, TSPO is clearly poised to affect cellular function and physiology. Based on Tspo knockout studies, this is via a primary function without impact on de novo steroid biosynthesis.

\section{CONCLUDING REMARKS}

This manuscript obviously represents a commendable effort by Papadopoulos and colleagues to seek evidence linking TSPO and mitochondrial cholesterol import for steroidogenesis. Nonetheless, previous demonstrations that TSPO is not involved in de novo steroidogenesis remain substantive and justified. Moving forward, we believe it is important to first acknowledge that high TSPO expression is not only seen in steroidogenic cells; a unifying investigation into mechanism of action across different cell types will be necessary to seek a functional designation for this protein.

\section{AUTHOR CONTRIBUTIONS}

VS wrote the first draft. KM, PK, JZ, WH, SQ, and DS made edits and revisions. All authors have made substantial intellectual contribution to the work and approved it for publication.

\section{ACKNOWLEDGMENTS}

We sincerely thank Dr. Richard Behringer (The University of Texas, MD Anderson Cancer Center) for his input on $A m h r 2^{t m 3(c r e) B h r}$ mice and impact of parental inheritance on 
Amhr2-cre activity. Funding for studies published by the authors with regard to Amhr2-cre and TSPO were from Cornell University startup funds to VS, NIH to VS (DK110059),
SQ (HD057648 and HD082536), and DS (HD17481), NSF ADVANCE program to SQ (0547373), NSFC to JZ (31471016), and a PUMC Scholarship to WH (3332015109).

\section{REFERENCES}

1. Fan J, Campioli E, Sottas C, Zirkin B, Papadopoulos V. Amhr2cre-mediated global Tspo knockout. J Endocr Soc. (2020) 4:bvaa001. doi: 10.1210/JENDSO/BVAA001

2. Selvaraj V, Tu LN, Stocco DM. Crucial role reported for TSPO in viability and steroidogenesis is a misconception. commentary: conditional steroidogenic cell-targeted deletion of TSPO unveils a crucial role in viability and hormone-dependent steroid formation. Front Endocrinol. (2016) 7:91. doi: 10.3389/fendo.2016.00091

3. Morohaku K, Pelton SH, Daugherty DJ, Butler WR, Deng W, Selvaraj V. Translocator protein/peripheral benzodiazepine receptor is not required for steroid hormone biosynthesis. Endocrinology. (2014) 155:89-97. doi: 10.1210/en.2013-1556

4. Jamin SP, Arango NA, Mishina Y, Hanks MC, Behringer RR. Requirement of Bmprla for Müllerian duct regression during male sexual development. Nat Genet. (2002) 32:408-10. doi: 10.1038/ng1003

5. Migone FF, Hung P-H, Cowan RG, Selvaraj V, Suarez SS, Quirk SM. Overactivation of hedgehog signaling in the developing Müllerian duct interferes with duct regression in males and causes subfertility. Reproduction. (2017) 153:481-92. doi: 10.1530/REP-16-0562

6. Migone FF, Cowan RG, Williams RM, Gorsea KJ, Zipfel WR, Quirk SM. In vivo imaging reveals an essential role of vasoconstriction in rupture of the ovarian follicle at ovulation. Proc Natl Acad Sci USA. (2016) 113:2294-9. doi: $10.1073 /$ pnas. 1512304113

7. Ren Y, Cowan RG, Harman RM, Quirk SM. Dominant activation of the hedgehog signaling pathway in the ovary alters theca development and prevents ovulation. Mol Endocrinol. (2009) 23:711-23. doi: 10.1210/me.2008-0391

8. Harman RM, Cowan RG, Ren Y, Quirk SM. Reduced signaling through the hedgehog pathway in the uterine stroma causes deferred implantation and embryonic loss. Reproduction. (2011) 141:665-74. doi: 10.1530/REP-10-0468

9. Ren Y, Cowan RG, Migone FF, Quirk SM. Overactivation of hedgehog signaling alters development of the ovarian vasculature in mice. Biol Reprod. (2012) 86:174. doi: 10.1095/biolreprod.112.099176

10. Zhang XM, Ramalho-Santos M, McMahon AP. Smoothened mutants reveal redundant roles for Shh and Ihh signaling including regulation of L/R asymmetry by the mouse node. Cell. (2001) 106:781-92. doi: 10.1016/S0092-8674(01)00385-3

11. Jamin SP, Arango NA, Mishina Y, Hanks MC, Behringer RR. Genetic studies of the AMH/MIS signaling pathway for Müllerian duct regression Mol Cell Endocrinol. (2003) 211:15-9. doi: 10.1016/j.mce.2003. 09.006

12. Jeyasuria P, Ikeda Y, Jamin SP, Zhao L, de Rooij DG, Themmen APN, et al. Cell-specific knockout of steroidogenic factor 1 reveals its essential roles in gonadal function. Mol Endocrinol. (2004) 18:1610-9. doi: 10.1210/me.2003-0404

13. Tsai MY, Yeh SD, Wang RS, Yeh S, Zhang C, Lin HY, et al. Differential effects of spermatogenesis and fertility in mice lacking androgen receptor in individual testis cells. Proc Natl Acad Sci USA. (2006) 103:18975-80. doi: 10.1073/pnas.0608565103

14. $\mathrm{Xu} \mathrm{Q}$, Lin $\mathrm{HY}$, Yeh SD, Yu IC, Wang RS, Chen YT, et al. Infertility with defective spermatogenesis and steroidogenesis in male mice lacking androgen receptor in Leydig cells. Endocrine. (2007) 32:96-106. doi: 10.1007/s12020-007-9015-0

15. Sen A, Hammes SR. Granulosa cell-specific androgen receptors are critical regulators of ovarian development and function. Mol Endocrinol. (2010) 24:1393-403. doi: 10.1210/me.2010-0006

16. Liu Z, Castrillon DH, Zhou W, Richards JAS. FOXO1/3 depletion in granulosa cells alters follicle growth, death and regulation of pituitary FSH. Mol Endocrinol. (2013) 27:238-52. doi: 10.1210/me.2012-1296
17. Hadji A, Ceppi P, Murmann AE, Brockway S, Pattanayak A, Bhinder B, et al. Death induced by CD95 or CD95 ligand elimination. Cell Rep. (2014) 7:208-22. doi: 10.1016/j.celrep.2014.02.035

18. Park JH, Tanaka Y, Arango NA, Zhang L, Benedict LA, Roh MI, et al. Induction of WNT inhibitory factor 1 expression by müllerian inhibiting substance/antimullerian hormone in the müllerian duct mesenchyme is linked to müllerian duct regression. Dev Biol. (2014) 386:227-36. doi: 10.1016/j.ydbio.2013.12.015

19. Dorfman MD, Garcia-Rudaz C, Alderman Z, Kerr B, Lomniczi A, Dissen GA, et al. Loss of NTRK2/KISS1R signaling in oocytes causes premature Ovarian failure. Endocrinology. (2014) 155:3098-111. doi: 10.1210/en.2014-1111

20. Ferguson L, Kaftanovskaya EM, Manresa C, Barbara AM, Poppiti RJ, Tan Y, et al. Constitutive notch signaling causes abnormal development of the oviducts, abnormal angiogenesis, and cyst formation in mouse female reproductive tract1. Biol Reprod. (2016) 94:1-12. doi: 10.1095/biolreprod.115.134569

21. Wang X, Mittal P, Castro CA, Rajkovic G, Rajkovic A. Med12 regulates ovarian steroidogenesis, uterine development and maternal effects in the mammalian egg. Biol Reprod. (2017) 97:822-34. doi: 10.1093/biolre/iox143

22. Mishina Y, Rey R, Finegold MJ, Matzuk MM, Josso N, Cate RL, et al. Genetic analysis of the Mullerian-inhibiting substance signal transduction pathway in mammalian sexual differentiation. Genes Dev. (1996) 10:2577-87. doi: $10.1101 /$ gad.10.20.2577

23. Selvaraj V, Stocco DM, Tu LN. Minireview: translocator protein (TSPO) and steroidogenesis: a reappraisal. Mol Endocrinol. (2015) 29:490-501. doi: 10.1210/me.2015-1033

24. Tu LN, Morohaku K, Manna PR, Pelton SH, Butler WR, Stocco DM, et al. Peripheral benzodiazepine receptor/translocator protein global knock-out mice are viable with no effects on steroid hormone biosynthesis. J Biol Chem. (2014) 289:27444-54. doi: 10.1074/jbc.M114.578286

25. Banati RB, Middleton RJ, Chan R, Hatty CR, Wai-Ying Kam W, Quin $\mathrm{C}$, et al. Positron emission tomography and functional characterization of a complete PBR/TSPO knockout. Nat Commun. (2014) 5: 5452. doi: $10.1038 /$ ncomms6452

26. Wang H, Zhai K, Xue Y, Yang J, Yang Q, Fu Y, et al. Global deletion of TSPO does not affect the viability and gene expression profile. PLOS ONE. (2016) 11:e0167307. doi: 10.1371/journal.pone.0167307

27. Barron AM, Ji B, Kito S, Suhara T, Higuchi M. Steroidogenic abnormalities in translocator protein knockout mice and significance in the aging male. Biochem J. (2018) 475:75-85. doi: 10.1042/BCJ20170645

28. Klee K, Storti F, Barben M, Samardzija M, Langmann T, Dunaief J, et al. Systemic knockout of Tspo in mice does not affect retinal morphology, function and susceptibility to degeneration. Exp Eye Res. (2019) 188:107816. doi: 10.1016/j.exer.2019.107816

29. Papadopoulos V, Amri H, Boujrad N, Cascio C, Culty M, Garnier $\mathrm{M}$, et al. Peripheral benzodiazepine receptor in cholesterol transport and steroidogenesis. Steroids. (1997) 62:21-8. doi: 10.1016/s0039-128x(96)00154-7

30. Anholt RR, De Souza EB, Oster-Granite ML, Snyder SH. Peripheraltype benzodiazepine receptors: autoradiographic localization in whole-body sections of neonatal rats. J Pharmacol Exp Ther. (1985) 233:517-26.

31. De Souza EB, Anholt RR, Murphy KM, Snyder SH, Kuhar MJ. Peripheral-type benzodiazepine receptors in endocrine organs: autoradiographic localization in rat pituitary, adrenal, and testis. Endocrinology. (1985) 116:567-73. doi: 10.1210/endo-116-2-567

32. Tu LN, Zhao AH, Hussein M, Stocco DM, Selvaraj V. Translocator protein (TSPO) affects mitochondrial fatty acid oxidation in steroidogenic cells. Endocrinology. (2016) 157:1110-21. doi: 10.1210/en.2015-1795

33. Stocco DM, Zhao AH, Tu LN, Morohaku K, Selvaraj V. A brief history of the search for the protein(s) involved in the acute regulation of steroidogenesis. Mol Cell Endocrinol. (2017) 441:7-16. doi: 10.1016/j.mce.2016.07.036 
34. Tu LN, Zhao AH, Stocco DM, Selvaraj V. PK11195 effect on steroidogenesis is not mediated through the translocator protein (TSPO). Endocrinology. (2015) 156:1033-9. doi: 10.1210/en.2014-1707

35. Milenkovic VM, Slim D, Bader S, Koch V, Heinl ES, Alvarez-Carbonell D, et al. CRISPR-cas9 mediated TSPO gene knockout alters respiration and cellular metabolism in human primary microglia cells. Int J Mol Sci. (2019) 20:3359. doi: $10.3390 /$ ijms 20133359

36. Fan J, Campioli E, Midzak A, Culty M, Papadopoulos V. Conditional steroidogenic cell-targeted deletion of TSPO unveils a crucial role in viability and hormone-dependent steroid formation. Proc Natl Acad Sci USA. (2015) 112:7261-6. doi: 10.1073/pnas.1502670112

37. Owen DR, Fan J, Campioli E, Venugopal S, Midzak A, Daly E, et al. TSPO mutations in rats and a human polymorphism impair the rate of steroid synthesis. Biochem J. (2017) 474:3985-99. doi: 10.1042/BCJ20170648

38. Fan J, Wang K, Zirkin B, Papadopoulos V. CRISPR/Cas9-mediated Tspo gene mutations lead to reduced mitochondrial membrane potential and steroid formation in MA-10 mouse tumor leydig cells. Endocrinology. (2018) 159:1130-46. doi: 10.1210/en.2017-03065

39. Selvaraj V, Stocco DM. Letter to the editor: dubious conclusions on TSPO function. Endocrinology. (2018) 159:2528-9. doi: 10.1210/en.2018-00052

40. Daugherty DJ, Chechneva O, Mayrhofer F, Deng W. The hGFAPdriven conditional TSPO knockout is protective in a mouse model of multiple sclerosis. Sci Rep. (2016) 6:22556. doi: 10.1038/srep 22556

41. Alamri A, Biswas L, Watson DG, Shu X. Deletion of TSPO resulted in change of metabolomic profile in retinal pigment epithelial cells. Int J Mol Sci. (2019) 20:1387. doi: 10.3390/ijms20061387

42. Šileikyte J, Blachly-Dyson E, Sewell R, Carpi A, Menabò R, Di Lisa F, et al. Regulation of the mitochondrial permeability transition pore by the outer membrane does not involve the peripheral benzodiazepine receptor (translocator protein of $18 \mathrm{kDa}$ (TSPO)). J Biol Chem. (2014) 289:13769-81. doi: 10.1074/jbc.M114.549634

Conflict of Interest: The authors declare that the research was conducted in the absence of any commercial or financial relationships that could be construed as a potential conflict of interest.

Copyright (c) 2020 Selvaraj, Morohaku, Koganti, Zhang, He, Quirk and Stocco. This is an open-access article distributed under the terms of the Creative Commons Attribution License (CC BY). The use, distribution or reproduction in other forums is permitted, provided the original author(s) and the copyright owner(s) are credited and that the original publication in this journal is cited, in accordance with accepted academic practice. No use, distribution or reproduction is permitted which does not comply with these terms. 